\title{
DERMATOMICOSE POR MICROSPORUM NANUM EM CRIAÇÃO DE SUÍNOS:
}

Eduardo do Nascimento MÓS*

Claudete Rodrigues de PAULA **

Leone MOTT JÚNIOR***

RFMV-A/21

MÓS, E. N.; PAULA, C. R.; MOTT JÚNIOR, L. Dermatomicose por Microsporum nanum em criação de suínos. Rev. Fac. Med. Vet. Zootec. Univ. S. Paulo, 15 (2):-159-60, 1978.

RESUMO: Os autores apresentam casos de dermatite micótica em sete animais de uma criação de suínos de raça Landrace, no Município de São Roque, Estado de São Paulo. Todos os animais apresentavam no tórax, lesôes cutâneas, irregulares, de aspecto ligeiramente rugoso, às vezes crostosas, de tonalidade castanha, circundadas por acentuado halo hiperêmico. $O$ diagnóstico estabeleceu-se após raspagem das lesões, seguindo-se exame direto e cultura do material, concluindo-se por dermatomicose causada por Microsporum nanum.

UNITERMOS: Dermatomicose, suínos*; Microsporum nanum.

\section{INTRODUÇÃO}

Comparativamente ao que ocorre com gatos, cães, bovinos e eqüinos, as referências sobre dermatomicoses em suínos são, ao contrário das já mencionadas, bastante escassas. Entre os agentes dessas micoses em suínos, BUXTON \& FRASER ${ }^{2}$ referem-se somente ao Trichophyton mentagrophytes e Trichophyton verrucosum, além do Microsporum nanum, fato este não confirmado por HORTER ${ }^{8}$ que encontrou Alternária em lesões de pele. Além destes, FISCHMAN \& SANTIAGO ${ }^{4}$, no Brasil, e PRIBOTH ${ }^{\circ}$, na Alemanha, isolaram o Microsporum canis de lesões da pele desses animais. Candida albicans ${ }^{3}$ também foi relacionada como agente de micose superficial em suínos.

\section{Material e métodos}

\section{Material}

\subsection{Suínos}

Sete suínos de uma criação apresentavam no tórax, lesões cutâneas bilaterais, irregulares no contorno, de aspecto ligeiramente rugoso e de tamanho variável. As lesōes menores apresentavam coloração avermelhada, enquanto as maiores, que atingiam até $20 \mathrm{~cm}$ de diâmetro, formavam crostas acastanhadas. Ao redor das lesões era notado o halo hiperêmico. (Fig. 1)

1.2 Escamas epidérmicas e pêlos Obtidas por raspagem nas bordas das lesões dos sete animais.

1.3. Meios de cultura

Foram utilizados os seguintes meios de cultura: Ágar-seletivo (Mycosel) e Ágar-Sabouraud dextrose com cloranfenicol - 10 $\mathrm{ug} / \mathrm{ml}$.

\section{Métodos}

Exame direto - Pêlos e escamas epidérmicas dos sete animais foram montados isoladamente, entre lâmina e lamínula, com solução de $\mathrm{KOH}$ a $20 \%$, para detectar esporos e filamentos ou artículos micelianos.

Cultura - Os raspados foram cultivados em ágar-seletivo (Mycosel), seguindo-se incubação a $25^{\circ} \mathrm{C}$ e $30^{\circ} \mathrm{C}$. As culturas obtidas foram repicadas em ágar-Sabouraud dextrose para obser-

\footnotetext{
* Professor Livre Docente

* Auxiliar de Ensino

Instituto de Ciências Biomédicas da USP.

*** Acadêmico

Faculdade de Medicina Veterinária e Zootecnia da USP.
} 
vação de "colônias gigantes". O cultivo em lâmina foi efetuado para o exame microscópico das estruturas típicas de dermatófitos.

3. Resultados

3.1. Exame direto

O exame direto dos pêlos revelou parasitismo intenso tipo ectothrix, com grandes esporos em cadeia em sua superfície e inúmeras hifas hialinas bastante refringentes nas escamas epidérmicas.

\subsection{Cultura}

Ao $8^{\circ}$ dia, as colônias apareciam de aspecto pulverulento, friáveis, de superfície camurça e reverso marrom-avermelhado. $\mathrm{O}$ exame microscópico, tanto a partir das culturas iniciais, como das obtidas pelos microcultivos, revelou macroaleuriosporos elipsóides ou ovais, compostos de uma, duas ou três e raramente quatro células e microaleuriosporos claviformes (Fig.2). Nāo foram observadas hifas espiraladas, nem hifas em raquete.

\section{Discussão e conclusão}

O fungo isolado apresentou características macro e micromorfológicas do $M$. nanum.BENEKE ") chama a atenção para o fato de que, macromorfologicamente, variantes de $M$. gypseum sāo semelhantes ao $M$. nanum. Levando-se em conta, porém, que o fungo isolado apresenta número de compartimentos de seus macroconídios nunca superior a quatro e não em grande número, como é o caso do $M$. gypseum (mais de seis), além das formas destes piriformes ou obvóides, enquanto as daqueles ( $M$. gypseum) longos e elipsóides, os A A. concluíram que a espécie isolada é $M$. nanum. Interessante ressaltar que, embora não tenhamos encontrado citações desses dermatófitos na literatura nacional, é de se admitir ocorrência relativamente grande do mesmo em nossas criações, à semelhança do que foi observado nos EUA (7), quando a doença era até essa data considerada rara e a partir de então, em apenas um ano, inúmeros registros de casos puderam ser observados em criações de suínos de 13 Estados diferentes.$^{(5,6)}$.

RFMV-A/21

MÓS, E.N.; PAULA, C.R.; MOTT JÚNIOR, L. Ringworm caused by Microsporum nanum in a swine breeding. Rev. Fac. Med. Vet. Zootec. Univ. S.Paulo, 15 (2): 159-60), 1978

SUMMARY: Ringworm caused by Microsporum nanum in a swine breeding

The authors present 7 cases of ringworm in animals from São Paulo state Landrace swine breeding. Diagnosis was established by direct microscopic examination and culture of the material obtained by scrapping of the lesions. Ringworn caused by Microsporum nanum was characterized.

UNITERMS: Ringworm*; Microsporum nanum*.

\section{REFERENCIAS BIBLIOGRÁFICAS}

1 - BENEKE, S.E. Scope monograph of human mycoses. Michigan, Baiard A. Thomas, 1976

2 - BUXTON, A. \& FRASER, G. Animal microbiology. S.L., Blackwell Scientific Publ., 1977 - v. 1.

3 - DUNNE, H.W.\& LEMAN.A. Diseases of swine.4th ed. Ames, Yowa State University Press, 1975.

4 - Fischman, O. \& SANTIAGo, M. Microsporum canis infection of a pig. Mycopathologia, Den Haag, 30: 271, 1966.

5 - GINTHER, O.J. Clinical aspects of Microsporum nanum infection in swine.
J. Amer. Vet. Med. Ass., 146: 945-53, 1965.

6 - GINTHER, O.J. \& AJELlo, L. The prevalence of Microsporum nanum infection in swine. J. Amer. Vet. Med. Ass., 146: 361-5, 1964

7 - GINTHER, O.J.; BUBASH, G.R.;AJEL LO, L. Microsporum nanum infection in swine. Vet. Med., 89: 79-84, 1964.

8 - HORTER, R. Fungal flora of pigs with or without skin diseases. Dtsch. tierarztl. Wschr., 69: 717-9, 1962 .

9-PRIBOTH, W. Microsporum canis as cause of ringworm in piglets. $M h$. Vet. Med., 17: 521-6, 1962 . 